\title{
Predominant Role of Grafted Iron (III) Schiff-base Complex in Oxidation of gaseous and aqueous reactants: A visible Light Responsive photocatalyst
}

\author{
Taymaz Tabari $^{1 *}$, Seyedeh Shabnam Jamali ${ }^{2}$ and Seyed Khashayar Jamali ${ }^{2}$
}

\begin{abstract}
The visible light response and photocatalytic activities of covalently bonded iron(III)-Schiff base complex is evaluated by photooxidation of nitric oxide under visible light exposure. In addition, this study reports the existing of dominant active sites on the surface of grafted complex toward water adsorption, which leads to the generation of hydroxyl radicals under illumination. Moreover, the morphological analysis exhibits high surface area $\left(575 \mathrm{~m}^{2} / \mathrm{g}\right)$ with an average pore diameter of $21 \mathrm{~nm}$; in this context, XRD analysis shows that the characteristic peaks of the Schiff-base complex are covered by the amorphous structure of the silica network, however, the microscopic analysis reveals the irregular shape of the grafted catalyst. Furthermore, the catalytic activity was evaluated by photooxidation of reactive blue 13 dye in aqueous solution under ambient light illumination. Also, the reaction variables such as the amount of catalyst, $\mathrm{pH}$ value, concentration and temperature of the dye solution were studied and discussed in detail. It seems, the enhanced activity of the photocatalyst toward the dye decolourization is a consequence of its uniform surface, large surface area, fine particles and active surface for the water adsorption.
\end{abstract}


Keywords: Visible light responsive photocatalysis; NO photooxidation; dye decolourization; Hydroxyl radicals; microcalorimetry

\section{Introduction}

As a new functional group of porous and crystalline materials, metal organic frameworks (MOFs) represent versatile applications as a gas sensor, heterogeneous catalysis, a proton conductor, etc. [1-6]. In this case, the distinct applications, especially as a heterogeneous catalyst, is a consequence of their unique textural properties such as great porosity, crystallinity and thermal stability [7]. Moreover, this group of materials has been exploited in many of organic transformation reactions as homogeneous catalysts $[8,9]$. However, in a homogeneous mixture, the recyclability of the catalysts from the reaction mixture is a very demanding task, which, in the case of heterogeneous catalysts, a simple filtration can prevail on this obstacle [10]. Furthermore, mesoporous silica support, which constructed by $\mathrm{Si}-\mathrm{O}$ building blocks, originally has high specific surface area and become a matter of interest for researchers. Regarding their high surface area, this category of materials can play as a host for many guest molecules and provide a host-guest pair for further applications, especially in the field of photocatalysis [11]. In this context, the mesoporous structure prohibits catalyst agglomeration, which is vital to generate a uniform surface for catalytic and photocatalytic features [12].

On the other hand, for past few decades, with the development of textile industries, eradicating of the organic pollutants, such as reactive dyes from the environment have become a matter of concern. In this context, the reactive dye molecules removed by ecodestructive and environmentally aggressive methods that are non-catalytic, toxic and 
expensive [13-18]. However, many of researchers have asserted that organic dyes are easily photo-oxidized due to their lower oxidation potential, therefore, simultaneous determining of photocatalytic activity using a standard method is necessary. In the terms of standard method of photocatalytic activity assessment, the NO oxidation used by many researchers to appraise and/or determine the photocatalytic activity of metal oxides such as $\mathrm{TiO}_{2}$ [19-23]. Moreover, a suitable catalyst should meet the following criteria, it should be stable, inexpensive, effective and eco-friendly. As the earth abundant based catalysts can be an appropriate alternative for very expensive precious metal based catalysts; in this context, iron-based catalysts have been reported as cheap, stable and promising materials [24]. On the other hand, there are two categories of heterogeneous Schiff-base complexes [25,26]: the first type consists of "encapsulated" phases, which has been deciphered by weak static electronic interaction such as Van der Waals forces-physical interaction. According to this loose interaction, leaching of the complex is inevitable that could restrict the application of these materials as an efficient catalyst, thereby to overcome these issues the second category was introduced. In the latter class, organic moieties (Schiff-base complexes) were attached on the surface of the inorganic species (silica network) through covalent bonds-chemical interaction, which is quite strong- fabricate a single material from different counterparts. This interaction not only prepares opportunities to tailor the structure of the catalyst, but also the strict binding of the components leads to a great stability to the harsh environment $[27,28]$. Thus, Schiff-base complexes that immobilised in a mesoporous silica network showed a dramatic change in their stability and activity as a catalyst [29-33].

Furthermore, either adsorption capacity or narrow bandgap energy are crucial features of a photocatalyst. Consequently, synthesis of MOF-based photocatalysts that are bandgap tunable, stable and efficient as well as inexpensive have attracted public interest for a past 
few years. These materials: with a high specific surface area capable of adsorbing dye molecules on the surface that are covered by water and/or hydroxyl groups, and then activate the dye molecules to the excited states. Simultaneously, the silica network diminished the energy of the photoinduced electrons, which exited from valence to conduction bands of the photocatalyst. Therefore, a decrease in energy of excited electrons declined the charge carriers recombination's rate [34]. Consequently, the photoinduced electron-transfer reactions lead to the generation of strong oxidative species such as ${ }^{\bullet} \mathrm{OH},{ }^{-} \mathrm{O}_{2}$, and ${ }^{+\bullet} \mathrm{O}_{2} \mathrm{H}$ that are essential for photocatalytic dye degradation [35].

The present paper describes the synthesis of iron(III)Schiff-base complex, which is covalently bonded to a silica network ((GISC) (Figure. S1)). Visible light response and the photocatalytic activity of the prepared material also was tested by ISO-22197:2007(E) method, which is the standard method for determination of the feature by measuring the rate of NO oxidation. Furthermore, GISC was used toward reactive blue 13 (RB13) as an aqueous reactant, under visible light irradiation, to evaluate its photocatalytic activity. In this context, the effect of $\mathrm{pH}$ value, catalyst loading and dye concentration, as well as the temperature of the solution were studied diligently. Then, the heat of water adsorption was measured by adsorption microcalorimetry to evaluate the importance of hydroxyl groups. Finally, a hydroxyl radical-dependent mechanism is suggested for the dye degradation reaction.

\section{Experimental}

\section{Preparation of heterogeneous iron Schiff base complex (GISC)}

In order to the preparation of GISC, tetraethylorthosilicate (TEOS, Merck; purity> 99.9\%) was dissolved in anhydrous ethyl alcohol $\left(\mathrm{CH}_{3} \mathrm{CH}_{2} \mathrm{OH}\right.$, Merck; purity $\left.>99.9 \%\right)$ under stirring-15 $\mathrm{min}$ at room temperature. Next, 3-aminopropyl(trimethoxy)silane (APS) was 
added to the prior solution and was kept 15 min under constant stirring. Then, salicylaldehyde was added to the solution (TEOS + APS); the molar ratios of TEOS: APS: salicylaldehyde were 5:1:1. Afterwards, $\mathrm{Fe}\left(\mathrm{NO}_{3}\right)_{3} \cdot 9 \mathrm{H}_{2} \mathrm{O}(0.5 \mathrm{~mol})$ was gradually added to above solution and was heated $\left(80{ }^{\circ} \mathrm{C}\right)$ for $12 \mathrm{~h}$. Then, this was filtered, the obtained redbrown solid washed for three times (methanol: DMF, 50: 50 vol\%), and dried in air. Finally, the as-prepared photocatalyst was characterized by SEM (VP-1450), EDS(type Inca 400), high-resolution field emission HR-TEM (FEI Tecnai G2, Japan, using $300 \mathrm{kV}$ accelerating voltage), STM (SS1-Made in Iran), FTIR (IR58SXC, Nicolet), XRD (Rigaku Ultima instrument with $\mathrm{Cu} \mathrm{K}$ radiation $\left(=1.5408^{\circ} \mathrm{A}\right)$, operated at an accelerating voltage of $40 \mathrm{kV}$, and emission current of $44 \mathrm{~mA}$ ), BET (Micromeritics Gemini V) and UV-DRS (Varina-Carry 100 double beams). Furthermore, the heat of water adsorption was studied by microcalorimetry (Setaram-C80).

\subsection{Photocatalytic activity test}

\subsubsection{Photocatalytic oxidation of NO}

The experimental set-up and methodology were reported in the previous work [36] and largely conforms to the ISO standard [37]. However, in order to accommodate larger samples, the inner width of the reactor was made to be $10 \mathrm{~cm}$ that is larger than the standard one ( 7 $\mathrm{cm})$. The test setup was designed to provide a constant concentration of test gas flow into the reactor and over the sample surfaces. The visible light (60 W tungsten lamp) was used as an illumination source to test the photocatalytic activity of GISC toward nitric oxide. The produced gases in the photocatalytic oxidation of the reactant analysed using the $\mathrm{NO}_{\mathrm{x}}$ analyser (THERMO Scientific Model 42i NO-NO $2-\mathrm{NO}_{\mathrm{x}}$ Analyser). The experiment was conducted in the following manner: The test sample placed in the photoreactor and, the glass 
window was attached. Simultaneously, the flow was stabilised in an empty line that directly connected to the $\mathrm{NO}_{\mathrm{x}}$ analyser. Next, the test gas was allowed to flow over the sample in darkness and the change in the volume fraction of $\mathrm{NO}$ and $\mathrm{NO}_{\mathrm{x}}$ was recorded. After maintaining of the gas flow, the sample was exposed to visible light for 60 minutes and the $\mathrm{NO}_{\mathrm{x}}$ volume fraction was recorded under this condition; the percent yield of photocatalytic NO oxidation was conducted from:

$$
D \%=\frac{c_{0}-c_{t}}{c_{0}} \times 100
$$

Where $\mathrm{D}$ is the oxidation percentage, $\mathrm{C}_{0}$ is the initial concentration of the nitric oxide and $\mathrm{C}_{\mathrm{t}}$ is the outlet concentration of the nitric oxide. In this context, the photocatalytic oxidation of the nitric oxide in grafted iron(III) Schiff-base complex studied in the constant NO concentration $(1000 \mathrm{ppb})$, flow rate $\left(1000 \mathrm{ml} \mathrm{min}^{-1}\right)$.

\subsubsection{Photocatalytic oxidation of dye}

The dye decolourization tests were conducted in a batch-type reactor, which was exposed by visible light as irradiation source $(60 \mathrm{~W})$. A homemade beaker $(250 \mathrm{ml})$, as a reaction container, was used. This could be covered by a very thin glass lid to prevent any unwanted decrease in the volume of the suspension during the constant stirring. About $100 \mathrm{mg}$ of photocatalyst was dispersed in $50 \mathrm{~mL}$ of an aqueous solution containing $50 \mathrm{mgL}^{-1}$ of $\mathrm{RB} 13$ (Figure. S3). This suspension was kept under stirring (300 rpm) for $1 \mathrm{~h}$ in darkness to establish the adsorption-desorption equilibrium, and then, it was immediately exposed to visible light. Moreover, a centrifuge was used to separate the catalyst from the dye solution. Then the solution $(5 \mathrm{ml})$ is transferred to UV-Vis spectrophotometer (550-JASCO) and the 
photocatalytic reaction was monitored consecutively. The concentration of RB13 was derived from a standard curve based on the observations of the absorbance obtained at $\lambda_{\max }(596 \mathrm{~nm})$.

\subsection{Adsorption microcalorimetry}

The grafted iron(III) Schiff-base complex was investigated by adsorption microcalorimetry to assess its adsorption properties, whether the differential heat of adsorption or quantity of adsorbed gases. Microcalorimetry experiment was performed on Setaram-C80 heat flow calorimeter coupled to a multiport high-vacuum homemade glass manifold. A specific amount of the sample (approx. $500 \mathrm{mg}$ ) was taken into a sample cell, reference cell was taken as empty and together they are connected with a "T" shaped Pyrex connector. The sample was heated from room temperature to $200^{\circ} \mathrm{C}$ under vacuum and heated for $2 \mathrm{~h}$, then $3-4$ doses of helium gas were introduced into the system to remove any excess residue such as moisture or organic impurity from the system. Then, the system was heated for $4-5 \mathrm{~h}$ under vacuum at $200^{\circ} \mathrm{C}$ and then cooled down to the temperature $\left(50^{\circ} \mathrm{C}\right)$ where the further adsorption experiments were conducted. After that the temperature stabilised, small doses of test gas (water vapour) introduced consecutively as well as gradually to the system and allowed it to increase up to 50 Torr-until an equilibrium pressure. Then the obtained differential heats of the test gas adsorption were recorded as a function of its coverage. Further, the manifold degassed under vacuum for almost 30 minutes; adsorption study was performed in the same manner. Finally, the number and strength of active surface are obtained from the difference between the adsorbed gases from the first and second adsorption

\section{Results and Discussion}

\section{FT-IR spectroscopic study}


Infrared spectroscopy (Figure S4) was exploited to characterise the functional groups of GISC. The bands at 1085,963 , and $800 \mathrm{~cm}^{-1}$ ascribed to the asymmetric stretching of $\mathrm{Si}-\mathrm{O}-$ $\mathrm{Si}\left(v_{\mathrm{SiOSi}}\right)$, stretching vibrations of $\mathrm{Si}-\mathrm{OH}\left(\mathrm{v}_{\mathrm{SiOH}}\right)$, and symmetric stretching of $\mathrm{Si}-\mathrm{O}-\mathrm{Si}$ ( $v_{\text {SiOSi }}$ ), respectively. Moreover, the broadband at $3600-3200 \mathrm{~cm}^{-1}$ attributed to silanol groups of the inorganic support. Furthermore, the bands at $3100-2800 \mathrm{~cm}^{-1}$ and $1550-1250 \mathrm{~cm}^{-1}$ region corresponded to $\mathrm{N}-\mathrm{H}$ and $\mathrm{C}-\mathrm{H}$ vibrations, respectively [38], which is observed due to the successful linkage of (3-aminopropyl)trimethoxysilane (APS) to the inorganic support. Likewise, the band at $1630 \mathrm{~cm}^{-1}$ emerged due to the grafting of the photocatalyst-attributes to azomethine group. This band depicts a red-shift to lower frequencies compared to its free counterparts [39] due to attachment of $\mathrm{Fe}(\mathrm{III})$ to $\mathrm{C}=\mathrm{N}$ of azomethine [38].

\section{Microscopic analysis}

The microscopic analysis (SEM, HR-TEM, and STM) was used to appraise the morphology and particle size as well as crystallinity. Based on SEM (Figure 1), the image illustrates a fibrous morphology with an average length of $10 \mu \mathrm{m}$. However, the porosity of the photocatalyst could not be addressed with respect to the image, the surface looks rough, scaly and nearly fully covered with the particles in different size. Furthermore, the composition of GISC evaluated by EDS analysis; the spectrum reveals the existence of $\mathrm{Si}, \mathrm{Fe}, \mathrm{C}$, and $\mathrm{O}$ elements (Fig. S5).

The particle size and crystallinity of GISC was studied by HR-TEM which is illustrated in Figure 2 (a-b). It seems particles size as well as the shape are irregular and the bigger particles are recognisable in the image along with the variety of particle shapes such as spherical, oval and hexagonal. The image reveals particle sizes range from about 15-40 nm. Moreover, Figure 2b demonstrates a highly crystalline structure of GISC, with ordered plans 
of silica matrices. Although the iron complex introduced to the silica network, the structure was preserved and retained its crystallinity. Furthermore, the scanning tunnelling microscopy (STM) as an accurate method is exploited to determine the size of the particles. As it is shown in Figure 3a, the bright spots are higher than the dark ones, which are distributed on the surface in a uniform manner. Moreover, four particles were selected for quantitative measurements (Figure 3b); the average size and height are 15 and $5 \mathrm{~nm}$, respectively. Despite the fact that TEM illustrated the variety in size, the STM (particle size around $15 \mathrm{~nm}$ ) corroborated the XRD results. Likewise, notwithstanding the results obtained from SEM, the STM image shows a uniform growth of the nanoparticles on the surface of GISC. Consequently, microscopic analysis revealed that GISC is a porous material with a fine and uniform particle size distribution which is suitable for heterogeneous catalysis features.

$<$ Fig. 1 $>,<$ Fig. $2>,<$ Fig. 3 $>$

\section{Thermal analyses}

Thermogravimetric analysis was used to investigate the thermal stability of GISC (Figure S6). The thermal analysis shows a noticeable mass loss around $22.363 \%$ within $75{ }^{\circ} \mathrm{C}$ to 500 ${ }^{\circ} \mathrm{C}$, which can be attributed to volatilization of the ethanol as well as removing of organic species. In spite of the fact that the neat complexes are thermally stable up to $300{ }^{\circ} \mathrm{C}[40,41]$, TGA result implies that the GISC have higher thermal stability than their homogeneous counterparts. The thermal stability of the photocatalyst is an evidence for effective immobilisation of the Schiff-base complex.

\section{Textural properties ( $N_{2}$ adsorption-desorption and XRD)}


The specific surface area $\left(575 \mathrm{~m}^{2} / \mathrm{g}\right)$ and pore size distribution $(21 \mathrm{~nm})$ of GISC was investigated by BET and BJH methods, respectively (Figure. 4a). Moreover, the adsorptiondesorption type is IV, this isotherm is characterised by a hysteresis loop is the characteristic of adsorption-desorption on mesoporous solids-this type of hysteresis loop ascribes to cylindrical and/or the 'ink bottle' pores [42]. The mesoporous nanostructures with a high surface area not only is crucial to enhance the photocatalytic activity but also provides necessary active sites to accelerate the diffusion of the reactant and product through the surface. In addition, the crystalline structure of GISC is examined by Powder XRD (Figure 4b). The broad peak at $2 \Theta$ of $19^{\circ}-30^{\circ}$ corresponds to the amorphous silica structure, which could be emerged by the coherent interaction of organic (Schiff-base ligand) and inorganic (silica support) species [25]. In other words connecting of the complex may not change the order of the silica matrices. On the other hand, it seems that the specific pattern of the Schiffbase complex is covered by the silica network.

$<$ Figure.4 $>$

\section{UV-Vis diffuse reflectance spectroscopy (UV-vis DRS)}

The UV-vis DRS spectra, which is shown in Figure 5a, provides important information about the optical properties of the photocatalyst-this was recorded in the range of 200 to $800 \mathrm{~nm}$. The DRS shows two characteristic bands for GISC at 275 and $335 \mathrm{~nm}$ that attributed to $\pi \rightarrow \pi^{*}$ and $\mathrm{n} \rightarrow \pi^{*}$ transitions, respectively. Moreover, a broadband centred at $570 \mathrm{~nm}$ was also detected that ascribed to d-d transition $[43,44]$. Furthermore, the phenyl rings exposed a peak at $275 \mathrm{~nm}$, which corresponded to the $\mathrm{n} \rightarrow \pi^{*}$ transition, whereas the band located in the range of $384-420 \mathrm{~nm}$ ascribed to $\mathrm{n} \rightarrow \pi^{*}$ transition of $C=N$ group. The energy of the bands at 570 $\mathrm{nm}$ due to the $\mathrm{d}-\mathrm{d}$ transition are analogous with the $\mathrm{T}_{2} \mathrm{~g} \rightarrow \mathrm{E}_{2} \mathrm{~g}$ transition of the iron(III). In 
addition, the photocatalyst exhibits multiple high-intensity charge transfer (CT) and intraligand bands in the range of $260-430 \mathrm{~nm}$. The CT and $\mathrm{d}-\mathrm{d}$ transitions corroborate the successful attachment of Fe(III) to the Schiff-base ligand. As Figure 5b illustrated, the optical band gap of GISC is $2.7 \mathrm{eV}$, it reveals that the GISC nanoparticles are a visible light responsive photocatalyst.

$<$ Fig. 5 $>$

\section{Photocatalytic study}

\section{1. photooxidation of nitric oxide}

The NO oxidation was used as a diagnostic method to determine the photocatalytic activity of GISC. Before the illumination, the surface of the reactor shielded with an aluminium foil, then NO admitted to the reactor until the NO concentration was found to be stable for a 10 minute. At the first moment of NO introducing to the reactor, the concentration decreased steeply and after a minute it backs to initial concentration, it seems the dilution of NO in the empty reactor is the major reason for this decrease and increase. Then, the aluminium foil removed and the photocatalytic reaction started by visible light exposure. As Figure 6 shows, a dramatic decrease in the NO concentration was observed upon the illumination, and $32 \%$ of $\mathrm{NO}$ is converted to $\mathrm{NO}_{\mathrm{x}}$. It seems, this enhanced activity at the beginning of illumination is a consequence of the light absorption by the catalyst. Eventually, this result implies that the grafted iron(III) Schiff-base complex is activated by the irradiation.

$<$ Fig. 6>

\subsection{Photocatalytic Dye decolourization}


The photocatalytic activity of the grafted Schiff-base complex is evaluated toward RB13 by varying the terms of the reaction such as the different amount of the photocatalyst, different $\mathrm{pH}$ values, different temperature and initial dye concentration to obtain the optimal condition of the dye decolourization.

\subsubsection{Effect of GISC's mass}

The dye degradation process can be affected by the amount of photocatalyst, which is suspended in the solution. It can affect the process by the light blocking, particles dispersion and agglomeration, as well as the facilitating the adsorption-desorption of reactants and/or intermediates-this assisted the generation/recombination of the charge carriers $[45,46]$. Hence the effects of photocatalyst's quantity on the dye decolourization is scrutinised in the range of 50 to $300 \mathrm{mg}$, whereas the dye concentration was $50 \mathrm{ppm}$ at $\mathrm{pH}=6$ (Fig. S7). Corresponding to this figure, a steep decrease in concentration of the dye versus irradiation time recorded with a rise in the photocatalyst's amount. The greatest percentage of decolorization observed at $100 \mathrm{mg}$ of the catalyst as a result of the optimal absorption of light and the dye on the surface that facilitates greater oxidation efficiency. In contrast, a slight decrease in efficiency is recorded for higher amounts of the catalyst (200 and $300 \mathrm{mg}$ ). Likewise, a lower oxidation efficiency observed below the optimal amount due to a lack of the number of active sites to the reactive species. In addition, above the optimal amount, the observed lower activity could be a consequence of particle-particle interaction and a simultaneous increase in the turbidity of the solution. In other words, the agglomeration and high turbidity inferior light absorption and facilitate the fast electron-hole recombination as well. Overall, the amount of loaded catalyst acts a major role in the oxidation of RB13, which converge the other researchers works [47-49]. 


\subsubsection{Effect of $\mathrm{pH}$ value}

Generation of active species involved in the oxidation of organic pollutants has stems in the surface charge of the photocatalyst. Corresponding to this, $\mathrm{pH}$ of the solution tuned to obtain the optimal condition (surface charge). Figure 7 displays the dye conversion percentage versus $\mathrm{pH}$; the highest yield of dye decolourization observed in the $\mathrm{pH}$ range of 4-6 (optimal $\mathrm{pH}$ centred at 6) that could be because of the surface's environment in terms of active species (hydroxyl radicals)-leads to indirect interaction between the catalyst and the reactant. In contrast, lowest activity obtained at highly acidic condition (pH 1 to 2), which can be due to direct and strong adsorption of the dye molecules with the catalyst surface; in other words, in the aggressive acidic condition, $\mathrm{pH}$ strongly interferes formation of hydroxyl groups [50]. Although the negative dye could directly adsorb at acidic condition on the positively charged surface, in the $\mathrm{pH}$ range between 4 and 6 weaker / indirect adsorption of dye molecule with the catalyst dominates the reaction. Thus, the mechanism of dye degradation highly dependent on $\mathrm{pH}$ value, via adjusting the active species on the surface. For instance, active species at lower $\mathrm{pHs}(\mathrm{pH}<3)$ are positive holes; whereas hydroxyl radicals are mostly responsible for the oxidation of the organic reactant at higher or neutral $\mathrm{pH}$ range [50]. $<$ Fig. $7>$

\subsubsection{Effect of temperature}

Temperature is dye-catalysts interaction nature's indicator, whether exothermic or endothermic. With respect to the issue, the dye decolourization over the grafted iron(III) Schiff-base complex was conducted at the different temperatures, $25,37,45$, and $58{ }^{\circ} \mathrm{C}$, which is shown in Figure S8. Increasing the temperature from 25 to $58{ }^{\circ} \mathrm{C}$ leads to a 
significant rise in the yield of the dye decolourization from 87.11 to $96.61 \%$, respectively. This increase demonstrates endothermic nature of the reaction. Therefore, the simultaneous rise in the yield of dye decolorization (with an increase in temperature of the solution) could be due to a rise in the reactant mobility [51].

\subsubsection{Effect of initial dye concentration}

The effect of initial concentration (10 to $100 \mathrm{ppm}$ ) on the yield of dye decolourization is investigated (Figure S9). As it illustrated; the RB13 decolourization is decreased by increasing the concentration. Notwithstanding the fact that an increase in concentration provides a driving force to overcome the resistance of mass transfer between the dye solution and the catalyst, the decolorization percentage decreased due to the shielding effect of dye with higher concentrations. In other words, a rise in the concentration of the reactive dye leads to raising of turbidity of the solution. Thus, the light could not penetrate the solution

and reach to the photocatalyst, result in a decline in the yield of dye decolourization from $98.21 \%$ to $84.82 \%$. As a matter of fact, the initial concentration of the RB13 solution converged the amount of the catalyst. In this context, despite the fact that the dye decolourization is related to the number of active sites proportion to the number of reactants is important, hindering the light by the higher concentration, whether catalyst or dye, is the main cause.

\subsubsection{Comparative study under irradiation and darkness}

A comparative study was conducted in the same manner, no proceed in the dye decolorization detected without photocatalyst, however, in the darkness, the photocatalyst can adsorb small amounts of the dye. Alternatively, the photocatalyst under light illumination shows an 
excellent dye decolorization performance; the results of these control experiments illustrated in Table S1. In addition, the RB13 solution was illuminated under ambient light for 40 minutes and no significant loss in concentration was obtained. Also, in the presence of GISC and visible light, decolourization is increased to $94.46 \%$. (Fig. 8). In the darkness, the GISC shows an insignificant activity toward the RB13-after 40 min it was declined mere 15\%. Apparently, the nature of dye decolourization in darkness not follows the photocatalytic manner. With the respect to the results, nanoparticles GISC exhibited higher dye decolorization activity as a visible light responsive photocatalyst (95\%). Regarding Figure 8, the main adsorption band of the dye locates at $596 \mathrm{~nm}$, as a result of the $\pi-\pi^{*}$ transition of azo form, and another band at $370 \mathrm{~nm}$ attributes to $\pi-\pi^{*}$ transition of naphthalene ring. Moreover, the photocatalyst under the light irradiation caused a decrease in the absorption bands of dye which could be due to the opening of benzene and naphthalene rings, however, the mentioned peaks are disappearing by the simultaneous rising of a new peak at $400 \mathrm{~nm}$. The change can be attributed to the formation and degradation of a naphthalene type intermediates and a solid evidence for photocatalytic degradation of the dye $[52,53]$. Eventually, the RB13 degradation was conducted in the presence of $\mathrm{TiO}_{2}$ as a photocatalyst, the result is presented in Figure $\mathrm{S} 10$. Corresponding to the graph, the reaction over $\mathrm{TiO}_{2}$ (Degussa-P25) followed with a slight decrease in the dye concentration under visible light irradiation. However, this photocatalyst indicated a drastic performance under UV irradiation (8 W fluorescent used as UV source). Despite this fact that $\mathrm{TiO}_{2}$ is a remarkable photocatalyst under UV illumination, GISC depicted as same performance as $\mathrm{TiO}_{2}$, under visible light exposure.

$<$ Figure $8>$ 


\section{Adsorption microcalorimetry}

Although carbon dioxide is the main probe molecule to assess the Lewis basicity, it does not consider the intrinsic effect of charge and radius of the metal ion on basicity. These play a vital role in the reactions, especially the ones that the surface involved. As it is known, the interaction of a cation and anion leads to the formation of the acid-base pair [54] that results in the stabilisation of counterparts whether anions or cations $[55,56]$. In order to tackle the issue, water may be regarded as a suitable molecule in surface chemistry. Water is a weakmedium ligand in the spectrochemical series of ligands which is also an amphoteric compound that makes it a suitable molecule that not only attaches to metal centre via oxygen atoms but also bond to oxygen of the metal oxide by hydrogens. Although, the adsorption of water as a Lewis base (ligand) can exclusively occur from the oxygen of water as a donor to metal centre and/or oxygen vacancy as an acceptor (Lewis Acid). In the terms of microcalorimetry, the adsorption of water on oxides like $\mathrm{Al}_{2} \mathrm{O}_{3}$ and $\mathrm{TiO}_{2}$ has been briefly studied by microcalorimetry [57-60], however, it is rare to find this type of studies on the grafted complexes especially immobilised Schiff-base ones. Regarding the issue, a number of active sites, as well as the strength of these sites measured by adsorption microcalorimetry. Figure 9a represents the differential heats of water adsorption versus the amount of adsorbed water vapour and the amount of adsorbed water versus pressure (Torr). The initial heat of water adsorption is $-789 \mathrm{~kJ} / \mathrm{mol}$ that extremely higher than that of the amounts reported for metal oxides [57-60]; indicates the great capacity of the sample toward adsorption of water. During the interaction of water with a basic surface, it acts as a proton donor: so, water can be adsorbed in a molecular mode and then dissociate to the expected species. The protonation of an anion $\mathrm{O}^{2-}$ and the formation of the hydroxyl group on the cations is a consequence of the dissociation of $\mathrm{O}-\mathrm{H}$ bond. The first layer coverage of water on the surface of the sample 
is $89.93 \mu \mathrm{mol} / \mathrm{g}$. These results correlate with photocatalysts nanostructure; smaller particle and mesoporous structure. It is worthwhile to mention that the grafted Schiff-base complex is too cheaper than precious metal doped equals and shows much higher activity for adsorption of water.

$<$ Figure 9 $>$

\section{Mechanism of photocatalytic dye decolourization}

The photocatalytic oxidation of organic reactant in aqueous solution may be started by the photo-excitation of the photocatalyst, which leads to the generation of charge carriers.

$$
\text { Catalyst }(h) \rightarrow h_{V B}^{+}+e_{C B}^{-}
$$

Also, the high oxidative potential of $\mathrm{h}^{+}$in the catalyst allows the direct oxidation of the reactant to reactive intermediates.

$$
\text { dye }+h_{v b}^{+} \rightarrow \text { dye } e^{--} \rightarrow \text { oxidation of dye }
$$

in addition, hydroxyl radical $\left({ }^{\bullet} \mathrm{OH}\right)$ is either formed by the decomposition of water or by the reaction of the hole with $-\mathrm{OH}$.

$$
\begin{gathered}
h^{+}+\mathrm{H}_{2} \mathrm{O} \rightarrow \mathrm{H}^{+}+\mathrm{HO}^{\circ} \\
h^{+}+\mathrm{HO}^{-} \rightarrow \mathrm{HO}^{*}
\end{gathered}
$$

moreover, adsorbed oxygen on the surface can absorb the electron at conduction band $\left(\mathrm{e}^{-} \mathrm{CB}\right)$ and generate another active species $\left({ }^{-\bullet} \mathrm{O}_{2}\right)$, which leads to the generation of ${ }^{-} \mathrm{OH},{ }^{-\bullet} \mathrm{OOH}$ and $-\mathrm{OOH}$ with respect to the following reactions.

$$
e_{C B}^{-}+O_{2} \rightarrow O_{2}^{-*}
$$




$$
\begin{gathered}
\mathrm{O}_{2}^{-*}+2 \mathrm{H}_{2} \mathrm{O} \rightarrow \mathrm{HOO}^{*}+2 \mathrm{HO}^{-} \\
2 \mathrm{HOO}^{*}+\mathrm{H}_{2} \mathrm{O}+e_{\mathrm{CB}}^{-} \rightarrow \mathrm{HOO}^{*}+2 \mathrm{HO}^{-} \\
2 \mathrm{HOO}^{*}+\mathrm{H}_{2} \mathrm{O}+e_{\mathrm{CB}}^{-} \rightarrow \mathrm{H}_{2} \mathrm{O}_{2}+\mathrm{HO}^{-} \\
\mathrm{H}_{2} \mathrm{O}_{2}+e_{\mathrm{CB}}^{-} \rightarrow \mathrm{HO}^{-}+\mathrm{HO}^{*} \\
\mathrm{H}_{2} \mathrm{O}_{2}+\mathrm{hv} \rightarrow 2 \mathrm{HO}^{*} \\
\text { dye }+\mathrm{O}_{2}^{-*} \rightarrow \text { oxidation } \\
\text { dye }+\mathrm{HO}^{*} \rightarrow \text { oxidation }
\end{gathered}
$$

corresponding to the microcalorimetry, the formation of hydroxyl radicals are plausible because of the capacity of the surface to adsorb the great amount of water with the high heat of adsorption. In this context, Menetrey, et. al., suggested dissociative adsorption mode, when the heat of water adsorption is higher than $-120 \mathrm{~kJ} / \mathrm{mol}$, while at the lower heat of adsorptions (lower than $-120 \mathrm{~kJ} / \mathrm{mol}$ ), it correlates with molecular mode [61]. Thus, in our cases, water adsorption on the grafted iron(III) Schiff-base complex comply the dissociative adsorption nature. Furthermore, the results of the photocatalytic experiment which performed in various $\mathrm{pH}$ values are in convergence with the microcalorimetry results; since the greatest activity obtained at $\mathrm{pH}=6$, which is a proper $\mathrm{pH}$ to the formation of hydroxyl groups. Apparently, hydroxyl groups play a major role in the degradation of the dye rather than other active species (hole and active oxygen). Moreover, the comparative study showed the importance of the illumination in the degradation process, in other words, the oxidation of dye initiated by 
light irradiation, and charge carrier generation that lead to the formation of hydroxyl radicals. Moreover, this radical is the most powerful oxidation agent $\left(\mathrm{E}^{\circ}=+3.06 \mathrm{~V}\right)$, whereas the active oxygen is a medium oxidation agent. Hence with respect to the $\mathrm{pH}$ and microcalorimetry results, the hydroxyl radicals play the main role in the oxidation of reactive blue 13. In this context, mesoporous structure of the grafted photocatalyst assists to prevent the fast charge carrier recombination. Overall, the grafted photocatalyst shows a great performance toward oxidation of the organic reactant.

\section{Conclusion}

This report argues the preparation of covalently bonded metal complex with aim of increasing the stability and activity of this category of materials. Despite the fact that the precious metal doped photocatalysts are widespread and shown great performance toward diverse contaminations, and an enormous number of publication are available about their surface characteristics, these materials are not cost effective as well as stable. Thus, covalently bonded complexes could be fruitful to gain much-needed insight into the photocatalysis outlook. In this work, iron(III)-Schiff base complex was covalently bonded to silica network by the sol-gel method. The physicochemical property of the material was studied by various methods, such as microscopic analysis (SEM, HR-TEM, and STM), textural analysis (BET and XRD) and optical analysis (UV-DRS) as well as FTIR and thermal analysis. The photocatalytic activity of grafted photocatalyst was evaluated by ISO-22197:2007(E) standard method and 42i-Thermo Scientific $\mathrm{NO}_{\mathrm{x}}$ analyser. In addition, the photocatalytic activity of the material was investigated thoroughly in term of catalyst amount, $\mathrm{pH}$, reactant concentration, and effect of temperature. In addition, the activity of the material under the light irradiation and the darkness were investigated and its influence in 
initiate of the reaction was characterised. Furthermore, we highlighted the main role of hydroxyl radicals as the active species in the oxidation of the RB13; the generation of these radicals followed by the heat of water adsorption, which measured by microcalorimetry. The results confirmed that the presence of iron(III) Schiff-complex on the surface leads to the generation of dominant active sites for water adsorption, which the heat of adsorption is extremely high in these spots. Consequently, the grafted iron(III) Schiff-base complex showed enhanced photocatalytic activity toward reactants whether NO or RB13 ascribed to the synergy effect of the mesoporous structure, optical property and the water adsorption (hydroxyl radical production) capacity of catalyst's dominant active sites (Schiff-base complex). This work suggests that the prepared photocatalyst may find other applications akin to attempting a full diversity of gaseous and aqueous reactants with a mechanistic approach.

\section{Acknowledgements}

The work was financially supported by Ferdowsi University of Mashhad (grant number: P/ 548). Special Thanks to Professor Hossein Eshtiagh-Hosseini and Dr. Reza Takjoo. Special Thanks to Professor Uner that let me use her laboratory facilities for testing of photocatalytic activity by the $\mathrm{NO}_{\mathrm{x}}$ analyser. Special thanks to Professor Ozkar for UV-DRS analysis and special thanks to members of Uner research group. We appreciate Dr Dheerendra Singh (Department of Energy Science and Engineering, Indian Institute of Technology Bombay) for his help and efforts in analysing of the microcalorimetry data as well as the HR-TEM images.

\section{References}


[1] S. El Mourabit, M. Guillot, G. Toquer, J. Cambedouzou, F. Goettmann, A. Grandjean, Stability of mesoporous silica under acidic conditions, RSC Adv. 2 (2012) 10916. doi: 10.1039/c2ra21569a.

[2] R.K. Sharma, S. Gulati, A. Pandey, A. Adholeya, Novel, efficient and recyclable silica based organic-inorganic hybrid Nickel catalyst for degradation of dye pollutants in a newly designed chemical reactor, Appl. Catal. B Environ. 125 (2012) 247-258. doi:10.1016/ j.apcatb.2012.05.046.

[3] M. Kruk, M. Jaroniec, A. Sayari, New insights into pore-size expansion of mesoporous silicates using long-chain amines, Microporous Mesoporous Mater. 35-36 (2000) 545-553. doi:10.1016/S1387-1811(99)00249-8.

[4] A. Modak, J. Mondal, V.K. Aswal, A. Bhaumik, A new periodic mesoporous organosilica containing diimine-phloroglucinol, $\mathrm{Pd}(\mathrm{ii})$-grafting and its excellent catalytic activity and trans-selectivity in C-C coupling reactions, J. Mater. Chem. 20 (2010) 8099. doi: 10.1039/c0jm01180k.

[5] S. Li, J. Zheng, D. Chen, Y. Wu, W. Zhang, F. Zheng, J. Cao, H. Ma, Y. Liu, Yolkshell hybrid nanoparticles with magnetic and $\mathrm{pH}$-sensitive properties for controlled anticancer drug delivery, Nanoscale. 5 (2013) 11718. doi:10.1039/c3nr04032a.

[6] W. Zhang, J. Zheng, C. Tan, X. Lin, S. Hu, J. Chen, X. You, S. Li, Designed selfassembled hybridAu@CdS core-shell nanoparticles with negative charge and their application as highly selective biosensors, J Mater Chem B. 3 (2015) 217-224. doi:10.1039/ C4TB01713G.

[7] T.F. Parangi, R.M. Patel, U.V. Chudasama, Synthesis and characterization of mesoporous Si-MCM-41 materials and their application as solid acid catalysts in some esterification reactions, Bull. Mater. Sci. 37 (2014) 609-615. doi:10.1007/ s12034-014-0709-7.

[8] M. Li, L. Liu, L. Zhang, X. Lv, J. Ding, H. Hou, Y. Fan, Novel coordination polymers of $\mathrm{Zn}$ (ii) and $\mathrm{Cd}(\mathrm{ii})$ tuned by different aromatic polycarboxylates: synthesis, structures and photocatalytic properties, CrystEngComm. 16 (2014) 6408. doi:10.1039/c4ce00093e.

[9] D. Chatterjee, E. Ember, U. Pal, S. Ghosh, R. van Eldik, Remarkably high catalytic activity of the RuIII(edta)/H2O2 system towards degradation of the azo-dye Orange II, Dalton Trans. 40 (2011) 10473. doi:10.1039/c1dt10483g.

[10] R.B.N. Baig, R.S. Varma, Magnetically retrievable catalysts for organic synthesis, Chem Commun. 49 (2013) 752-770. doi:10.1039/C2CC35663E.

[11] E. Borodina, S.I. Karpov, V.F. Selemenev, W. Schwieger, S. Maracke, M. Fröba, F. Rößner, Surface and texture properties of mesoporous silica materials modified by siliconorganic compounds containing quaternary amino groups for their application in basecatalyzed reactions, Microporous Mesoporous Mater. 203 (2015) 224-231. doi:10.1016/ j.micromeso.2014.10.009.

[12] C. Cheng, D. Lu, B. Shen, Y. Liu, J. Lei, L. Wang, J. Zhang, M. Matsuoka, Mesoporous silica-based carbon dot/TiO2 photocatalyst for efficient organic pollutant degradation, Microporous Mesoporous Mater. 226 (2016) 79-87. doi:10.1016/j.micromeso. 2015.12.043.

[13] S. Mortazavi-Derazkola, S. Zinatloo-Ajabshir, M. Salavati-Niasari, Novel simple solvent-less preparation, characterization and degradation of the cationic dye over holmium oxide ceramic nanostructures, Ceram. Int. 41 (2015) 9593-9601. doi:10.1016/j.ceramint. 2015.04.021. 
[14] Z. Salehi, S. Zinatloo-Ajabshir, M. Salavati-Niasari, Novel synthesis of $\mathrm{Dy}_{2} \mathrm{Ce}_{2} \mathrm{O}_{7}$ nanostructures via a facile combustion route, RSC Adv. 6 (2016) 26895-26901. doi:10.1039/ C5RA27919D.

[15] S. Zinatloo-Ajabshir, M. Salavati-Niasari, M. Hamadanian, Praseodymium oxide nanostructures: novel solvent-less preparation, characterization and investigation of their optical and photocatalytic properties, RSC Adv. 5 (2015) 33792-33800. doi:10.1039/ C5RA00817D.

[16] S. Zinatloo-Ajabshir, M. Salavati-Niasari, Z. Zinatloo-Ajabshir, Nd2Zr2O7-Nd2O3 nanocomposites: New facile synthesis, characterization and investigation of photocatalytic behaviour, Mater. Lett. 180 (2016) 27-30. doi:10.1016/j.matlet.2016.05.094.

[17] S. Zinatloo-Ajabshir, M. Salavati-Niasari, Nanocrystalline $\operatorname{Pr}{ }_{6} \mathrm{O}_{11}$ : synthesis, characterization, optical and photocatalytic properties, New J Chem. 39 (2015) 3948-3955. doi:10.1039/C4NJ02106A.

[18] S. Zinatloo-Ajabshir, M. Salavati-Niasari, Facile route to synthesize zirconium dioxide $(\mathrm{ZrO} 2)$ nanostructures: Structural, optical and photocatalytic studies, J. Mol. Liq. 216 (2016) 545-551. doi:10.1016/j.molliq.2016.01.062.

[19] Y.-M. Lin, Y.-H. Tseng, J.-H. Huang, C.C. Chao, C.-C. Chen, I. Wang, Photocatalytic Activity for Degradation of Nitrogen Oxides over Visible Light Responsive Titania-Based Photocatalysts, Environ. Sci. Technol. 40 (2006) 1616-1621. doi:10.1021/es051007p. [20] Y.-H. Tseng, C.-S. Kuo, C.-H. Huang, Y.-Y. Li, P.-W. Chou, C.-L. Cheng, M.-S. Wong, Visible-light-responsive nano- $\mathrm{TiO}_{2}$ with mixed crystal lattice and its photocatalytic activity, Nanotechnology. 17 (2006) 2490-2497. doi:10.1088/0957-4484/17/10/009.

[21] C.-S. Kuo, Y.-H. Tseng, C.-H. Huang, Y.-Y. Li, Carbon-containing nano-titania prepared by chemical vapor deposition and its visible-light-responsive photocatalytic activity, J. Mol. Catal. Chem. 270 (2007) 93-100. doi:10.1016/j.molcata.2007.01.031.

[22] Y.-C. Hsiao, Y.-H. Tseng, Preparation of Pd-containing TiO2 film and its photocatalytic properties, Micro Nano Lett. 5 (2010) 317. doi:10.1049/mnl.2010.0094.

[23] T. Sano, N. Negishi, K. Koike, K. Takeuchi, S. Matsuzawa, Preparation of a visible light-responsive photocatalyst from a complex of Ti4+ with a nitrogen-containing ligand, J. Mater. Chem. 14 (2004) 380. doi:10.1039/b311444a.

[24] P. Niu, J. Hao, Efficient degradation of organic dyes by titanium dioxidesilicotungstic acid nanocomposite films: Influence of inorganic salts and surfactants, Colloids Surf. Physicochem. Eng. Asp. 443 (2014) 501-507. doi:10.1016/j.colsurfa.2013.12.005. [25] J.-L. Liu, S. Xu, B. Yan, Photoactive hybrids with the functionalized Schiff-base derivatives covalently bonded inorganic silica network: Sol-gel synthesis, characterization and photoluminescence, Colloids Surf. Physicochem. Eng. Asp. 373 (2011) 116-123. doi: 10.1016/j.colsurfa.2010.10.036.

[26] H.R. Li, J. Lin, H.J. Zhang, L.S. Fu, Q.G. Meng, S.B. Wang, Preparation and Luminescence Properties of Hybrid Materials Containing Europium(III) Complexes Covalently Bonded to a Silica Matrix, Chem. Mater. 14 (2002) 3651-3655. doi:10.1021/ cm0116830.

[27] A.-C. Franville, D. Zambon, R. Mahiou, Y. Troin, Luminescence Behavior of Sol-Gel-Derived Hybrid Materials Resulting from Covalent Grafting of a Chromophore Unit to Different Organically Modified Alkoxysilanes, Chem. Mater. 12 (2000) 428-435. doi: $10.1021 / \mathrm{cm} 9904739$.

[28] X. Guo, H. Guo, L. Fu, L.D. Carlos, R.A.S. Ferreira, L. Sun, R. Deng, H. Zhang, 
Novel Near-Infrared Luminescent Hybrid Materials Covalently Linking with Lanthanide [Nd(III), Er(III), Yb(III), and Sm(III)] Complexes via a Primary $\beta$-Diketone Ligand: Synthesis and Photophysical Studies, J. Phys. Chem. C. 113 (2009) 12538-12545. doi: 10.1021/jp9005179.

[29] S.-C. Kim, B.-Y. Jeong, D.-K. Lee, Catalytic wet oxidation of reactive dyes in water, Top. Catal. 33 (2005) 149-154. doi:10.1007/s11244-005-2521-5.

[30] Priyanka, V.C. Srivastava, Photocatalytic Oxidation of Dye Bearing Wastewater by Iron Doped Zinc Oxide, Ind. Eng. Chem. Res. 52 (2013) 17790-17799. doi:10.1021/ ie401973r.

[31] W. Li, D. Li, J. Wang, Y. Shao, J. You, F. Teng, Exploration of the active species in the photocatalytic degradation of methyl orange under UV light irradiation, J. Mol. Catal. Chem. 380 (2013) 10-17. doi:10.1016/j.molcata.2013.09.001.

[32] U. Ashraf, O.A. Chat, A.A. Dar, An inhibitory effect of self-assembled soft systems on Fenton driven degradation of xanthene dye Rhodamine B, Chemosphere. 99 (2014) 199 206. doi:10.1016/j.chemosphere.2013.10.074.

[33] O. Merka, V. Yarovyi, D.W. Bahnemann, M. Wark, pH-Control of the Photocatalytic Degradation Mechanism of Rhodamine B over $\mathrm{Pb}_{3} \mathrm{Nb}_{4} \mathrm{O}_{13}$, J. Phys. Chem. C. 115 (2011) 8014-8023. doi:10.1021/jp108637r.

[34] G. Ramanjaneya Reddy, S. Balasubramanian, Synthesis, characterization and photocatalytic studies of mesoporous silica grafted $\mathrm{Ni}$ ( II ) and $\mathrm{Cu}$ ( II ) complexes, RSC Adv. 5 (2015) 53979-53987. doi:10.1039/C5RA07469J.

[35] C. Göl, M. Malkoç, S. Yeşilot, M. Durmuş, A first archetype of boron dipyrromethene-phthalocyanine pentad dye: design, synthesis, and photophysical and photochemical properties, Dalton Trans. 43 (2014) 7561. doi:10.1039/c4dt00406j.

[36] D. Uner, I. Bayar, T. Tabari, The influence of relative humidity on photocatalytic oxidation of nitric oxide (NO) over TiO2, Appl. Surf. Sci. 354 (2015) 260-266. doi:10.1016/ j.apsusc.2015.07.045.

[37] A. Mills, L. Burns, C. O'Rourke, S. Elouali, Kinetics of the photocatalysed oxidation of NO in the ISO 22197 reactor, J. Photochem. Photobiol. Chem. 321 (2016) 137-142. doi: 10.1016/j.jphotochem.2016.01.010.

[38] S. Bhunia, S. Koner, Tethering of nickel(II) Schiff-base complex onto mesoporous silica: An efficient heterogeneous catalyst for epoxidation of olefins, Polyhedron. 30 (2011) 1857-1864. doi:10.1016/j.poly.2011.04.040.

[39] A. Ghorbani-Choghamarani, B. Tahmasbi, F. Arghand, S. Faryadi, Nickel Schiff-base complexes immobilized on boehmite nanoparticles and their application in the oxidation of sulfides and oxidative coupling of thiols as novel and reusable nano organometal catalysts, RSC Adv. 5 (2015) 92174-92183. doi:10.1039/C5RA14974F.

[40] C. Lijuan, M. Fuming, L. Guangxing, Co(II) Schiff base complexes on silica by solgel method as heterogeneous catalysts for oxidative carbonylation of aniline, Catal. Commun. 10 (2009) 981-985. doi:10.1016/j.catcom.2008.12.047.

[41] A. Bezaatpour, S. Khatami, M. Amiri, Development of the catalytic reactivity of an oxo-peroxo Mo( VI ) Schiff base complex supported on supermagnetic nanoparticles as a reusable green nanocatalyst for selective epoxidation of olefins, RSC Adv. 6 (2016) 2745227459. doi:10.1039/C5RA27751E.

[42] O. Carmody, R. Frost, Y. Xi, S. Kokot, Surface characterisation of selected sorbent materials for common hydrocarbon fuels, Surf. Sci. 601 (2007) 2066-2076. doi:10.1016/ 
j.susc.2007.03.004.

[43] S. Gazi, A. Rajakumar, N.D.P. Singh, Photodegradation of organic dyes in the presence of [Fe(III)-salen] $\mathrm{Cl}$ complex and $\mathrm{H} 2 \mathrm{O} 2$ under visible light irradiation, J. Hazard. Mater. 183 (2010) 894-901. doi:10.1016/j.jhazmat.2010.07.113.

[44] A.R. Silva, K. Wilson, A.C. Whitwood, J.H. Clark, C. Freire, Amine-Functionalised Hexagonal Mesoporous Silica as Support for Copper(II) Acetylacetonate Catalyst, Eur. J. Inorg. Chem. 2006 (2006) 1275-1283. doi:10.1002/ejic.200500979.

[45] A. Franco, M.C. Neves, M.M.L.R. Carrott, M.H. Mendonça, M.I. Pereira, O.C. Monteiro, Photocatalytic decolorization of methylene blue in the presence of TiO2/ZnS nanocomposites, J. Hazard. Mater. 161 (2009) 545-550. doi:10.1016/j.jhazmat.2008.03.133. [46] B. Neppolian, S.R. Kanel, H.C. Choi, M.V. Shankar, B. Arabindoo, V. Murugesan, Photocatalytic degradation of reactive yellow 17 dye in aqueous solution in the presence of TiO2 with cement binder, Int. J. Photoenergy. 5 (2003) 45-49. doi:10.1155/ S1110662X03000126.

[47] H. Zhu, R. Jiang, Y. Fu, Y. Guan, J. Yao, L. Xiao, G. Zeng, Effective photocatalytic decolorization of methyl orange utilizing $\mathrm{TiO} 2 / \mathrm{ZnO} /$ chitosan nanocomposite films under simulated solar irradiation, Desalination. 286 (2012) 41-48. doi:10.1016/j.desal.2011.10.036. [48] M. Saquib, M. Abu Tariq, M.M. Haque, M. Muneer, Photocatalytic degradation of disperse blue 1 using UV/TiO2/H2O2 process, J. Environ. Manage. 88 (2008) 300-306. doi: 10.1016/j.jenvman.2007.03.012.

[49] S. Kaur, V. Singh, TiO2 mediated photocatalytic degradation studies of Reactive Red 198 by UV irradiation, J. Hazard. Mater. 141 (2007) 230-236. doi:10.1016/j.jhazmat.

2006.06.123.

[50] F.F. Dias, A.A.S. Oliveira, A.P. Arcanjo, F.C.C. Moura, J.G.A. Pacheco, Residuebased iron catalyst for the degradation of textile dye via heterogeneous photo-Fenton, Appl. Catal. B Environ. 186 (2016) 136-142. doi:10.1016/j.apcatb.2015.12.049.

[51] K.C. Gupta, H.K. Abdulkadir, S. Chand, Synthesis of polymer anchored N,N'-bis(3allyl salicylidene)o-phenylenediamine cobalt(II) Schiff base complex and its catalytic activity for decomposition of hydrogen peroxide, J. Mol. Catal. Chem. 202 (2003) 253-268. doi: 10.1016/S1381-1169(03)00209-7.

[52] M. Luo, L. Lv, G. Deng, W. Yao, Y. Ruan, X. Li, A. Xu, The mechanism of bound hydroxyl radical formation and degradation pathway of Acid Orange II in Fenton-like Co2+HCO3- system, Appl. Catal. Gen. 469 (2014) 198-205. doi:10.1016/j.apcata.2013.09.045.

[53] L. Duan, Y. Chen, K. Zhang, H. Luo, J. Huang, A. Xu, Catalytic degradation of Acid Orange 7 with hydrogen peroxide using $\mathrm{Co}_{\mathrm{x}} \mathrm{O}_{\mathrm{y}}-\mathrm{N} / \mathrm{GAC}$ catalysts in a bicarbonate aqueous solution, RSC Adv. 5 (2015) 84303-84310. doi:10.1039/C5RA13603B.

[54] H. Knözinger, S. Huber, IR spectroscopy of small and weakly interacting molecular probes for acidic and basic zeolites, J. Chem. Soc. Faraday Trans. 94 (1998) 2047-2059. doi: 10.1039/a802189i.

[55] M. Badlani, I.E. Wachs, Methanol: A "Smart" Chemical Probe Molecule, Catal. Lett. 75 (2001) 137-149. doi:10.1023/A:1016715520904.

[56] C. Chizallet, G. Costentin, H. Lauron-Pernot, J.M. Krafft, P. Bazin, J. Saussey, F. Delbecq, P. Sautet, M. Che, Role of Hydroxyl Groups in the Basic Reactivity of MgO: a Theoretical and Experimental Study, Oil Gas Sci. Technol. - Rev. IFP. 61 (2006) 479-488. doi:10.2516/ogst:2006023a.

[57] J.M. McHale, Surface Energies and Thermodynamic Phase Stability in 
Nanocrystalline Aluminas, Science. 277 (1997) 788-791. doi:10.1126/science.277.5327.788. [58] J.M. McHale, A. Navrotsky, A.J. Perrotta, Effects of Increased Surface Area and Chemisorbed $\mathrm{H}_{2} \mathrm{O}$ on the Relative Stability of Nanocrystalline $\gamma-\mathrm{Al}_{2} \mathrm{O}_{3}$ and $\alpha-\mathrm{Al}_{2} \mathrm{O}_{3}, \mathrm{~J}$. Phys. Chem. B. 101 (1997) 603-613. doi:10.1021/jp9627584.

[59] G. Li, L. Li, J. Boerio-Goates, B.F. Woodfield, High Purity Anatase TiO 2 Nanocrystals: Near Room-Temperature Synthesis, Grain Growth Kinetics, and Surface Hydration Chemistry, J. Am. Chem. Soc. 127 (2005) 8659-8666. doi:10.1021/ja050517g. [60] G. Li, L. Li, J. Boerio-Goates, B.F. Woodfield, Grain-growth kinetics of rutile TiO2 nanocrystals under hydrothermal conditions, J. Mater. Res. 18 (2003) 2664-2669. doi: $10.1017 / \mathrm{S} 0884291400065936$.

[61] M. Menetrey, A. Markovits, C. Minot, Reactivity of a reduced metal oxide surface: hydrogen, water and carbon monoxide adsorption on oxygen defective rutile TiO2(), Surf. Sci. 524 (2003) 49-62. doi:10.1016/S0039-6028(02)02464-0. 


\section{Figure caption}

Fig. 1. SEM micrograph of nanoparticles GISC prepared via sol-gel method.

Fig. 2. HR-TEM micrograph of nanoparticles GISC prepared via sol-gel method: (a) Low magnification, (b) High magnification.

Fig. 3. STM photograph: 3D photograph (a) and, height and size (b) of GISC nanoparticles.

Fig. 4. Nitrogen adsorption- desorption isotherm of nanoparticles GISC (a), and XRD pattern of the as-prepared photocatalyst.

Fig. 5. Optical properties: UV-DRS absorbance (a) and Band gap energy (b) of GISC nanoparticles.

Fig. 6. Time dependence decreases in the concentration of $\mathrm{NO}$ and $\mathrm{NO}_{\mathrm{x}}$ over photocatalyst nanoparticles (100 mg) under ambient light exposure.

Fig. 7. Effect of solution $\mathrm{pH}$ on photocatalytic oxidation of the RB13 dye using the asprepared photocatalyst.

Fig. 8. Temporal Absorbance spectral pattern of the reaction mixture within oxidation process on the as-prepared photocatalyst.

Fig. 9. Adsorption microcalorimetry; the heat of water adsorption (a) and coverage ( $\mu \mathrm{mol}$ water adsorbed per gramme of the photocatalyst (b). 


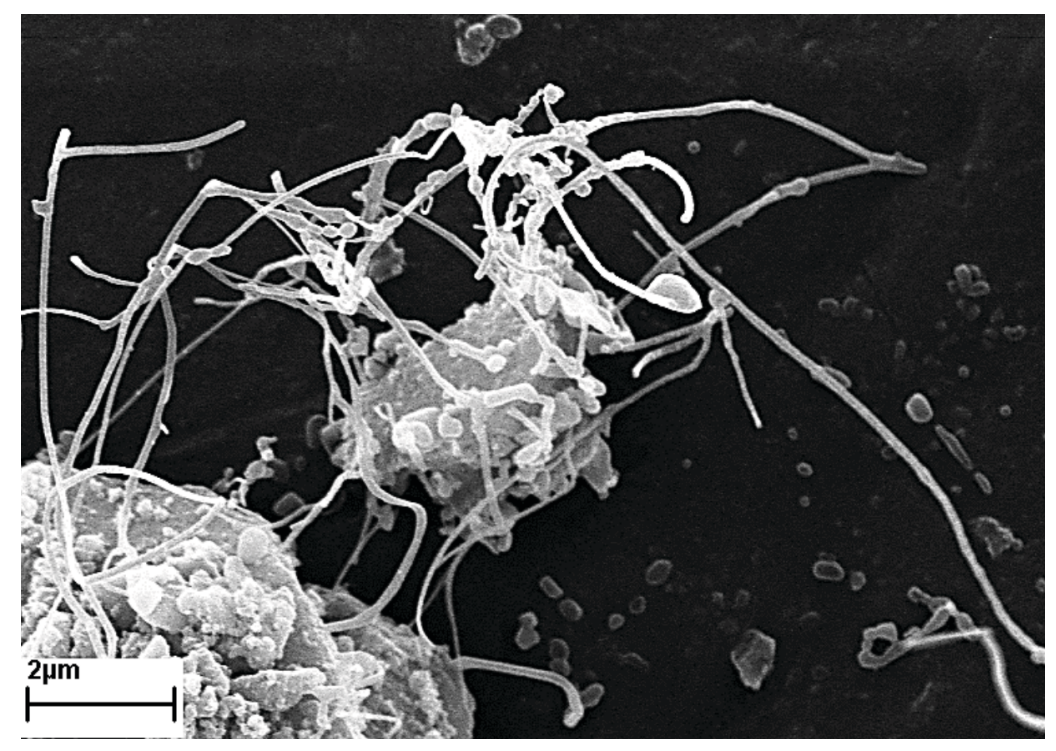

Fig. 1

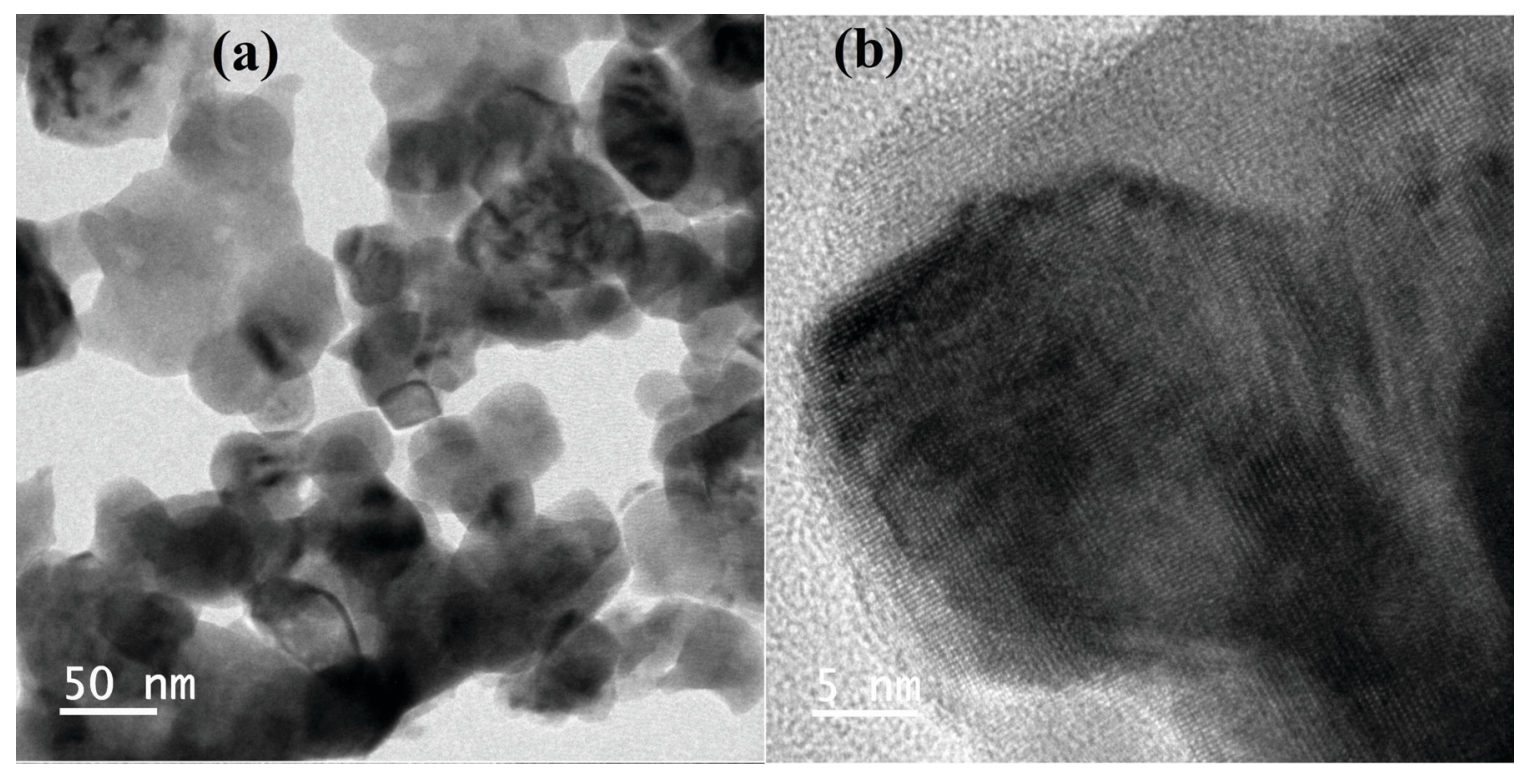

Fig. 2 


\section{a}
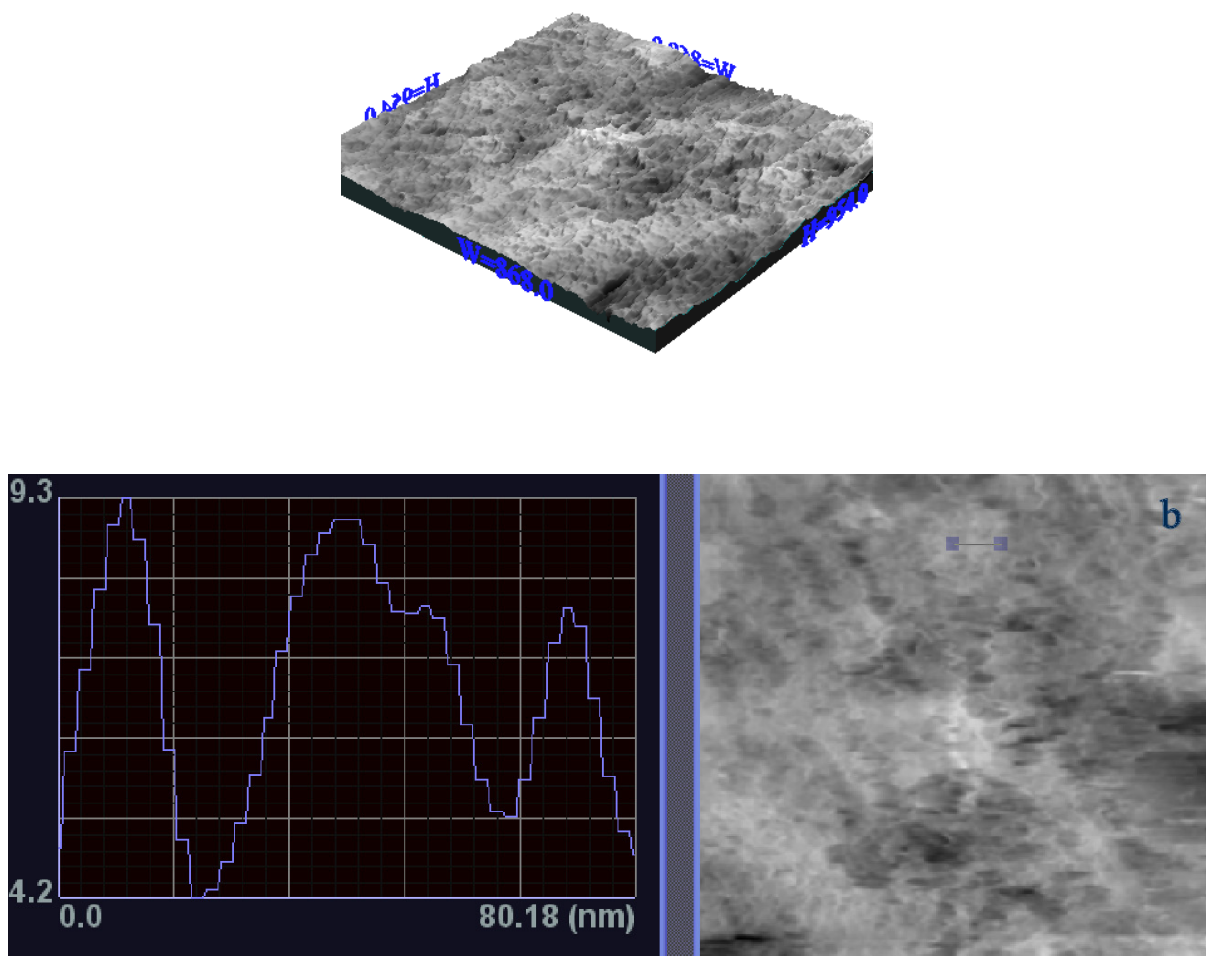

Fig. 3 

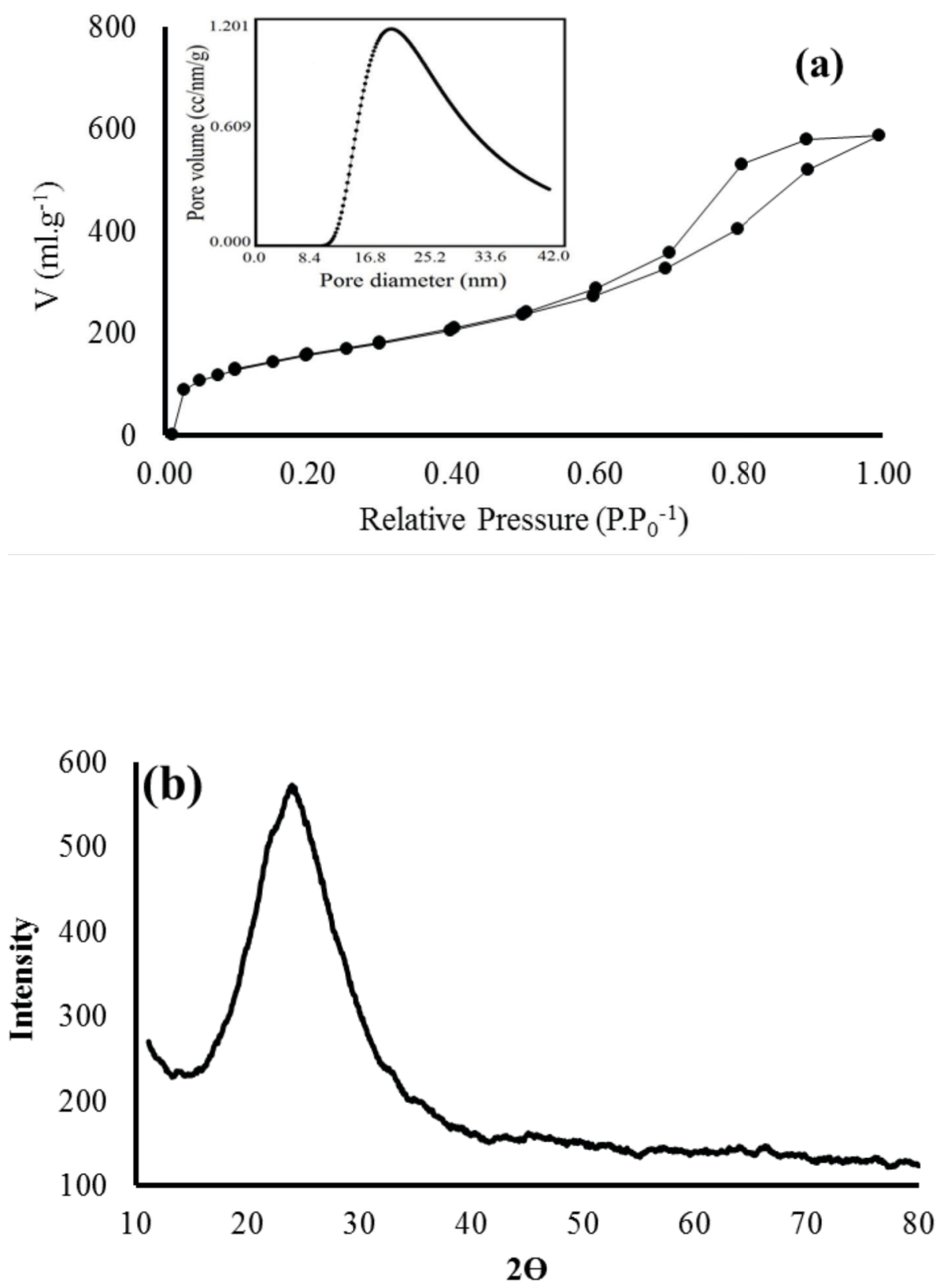

Fig. 4 

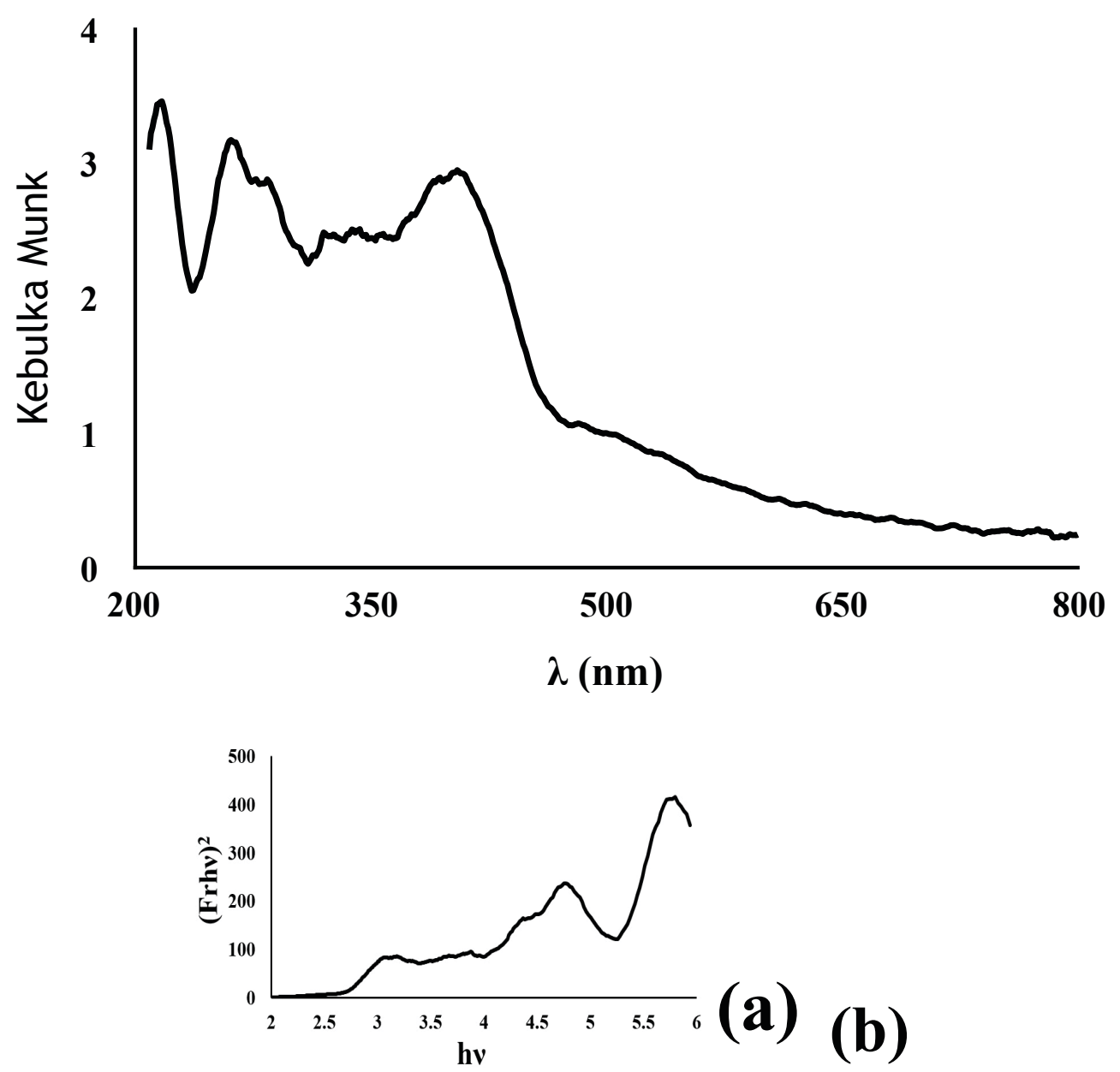

Fig. 5

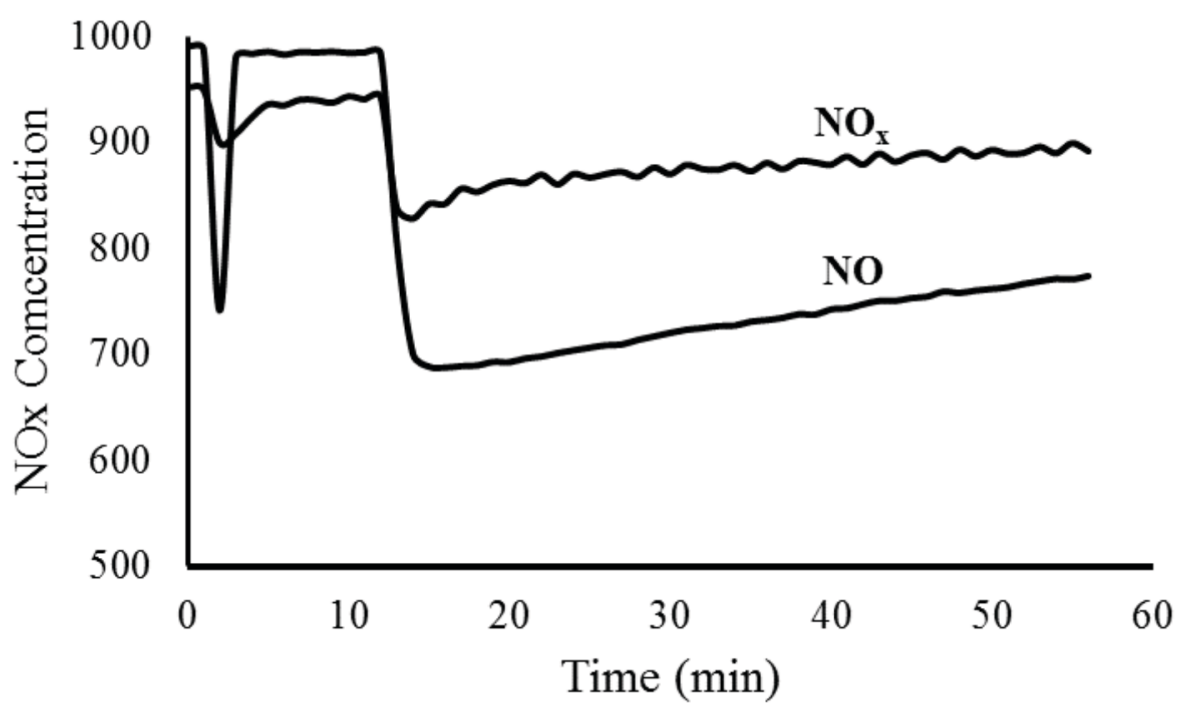


Fig. 6

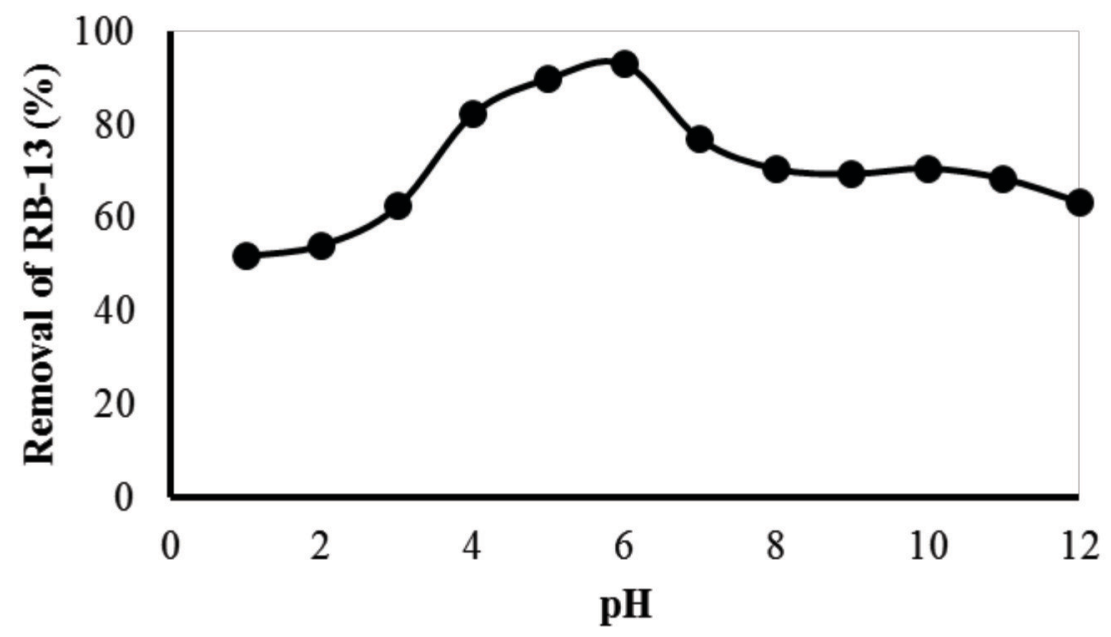

Fig. 7

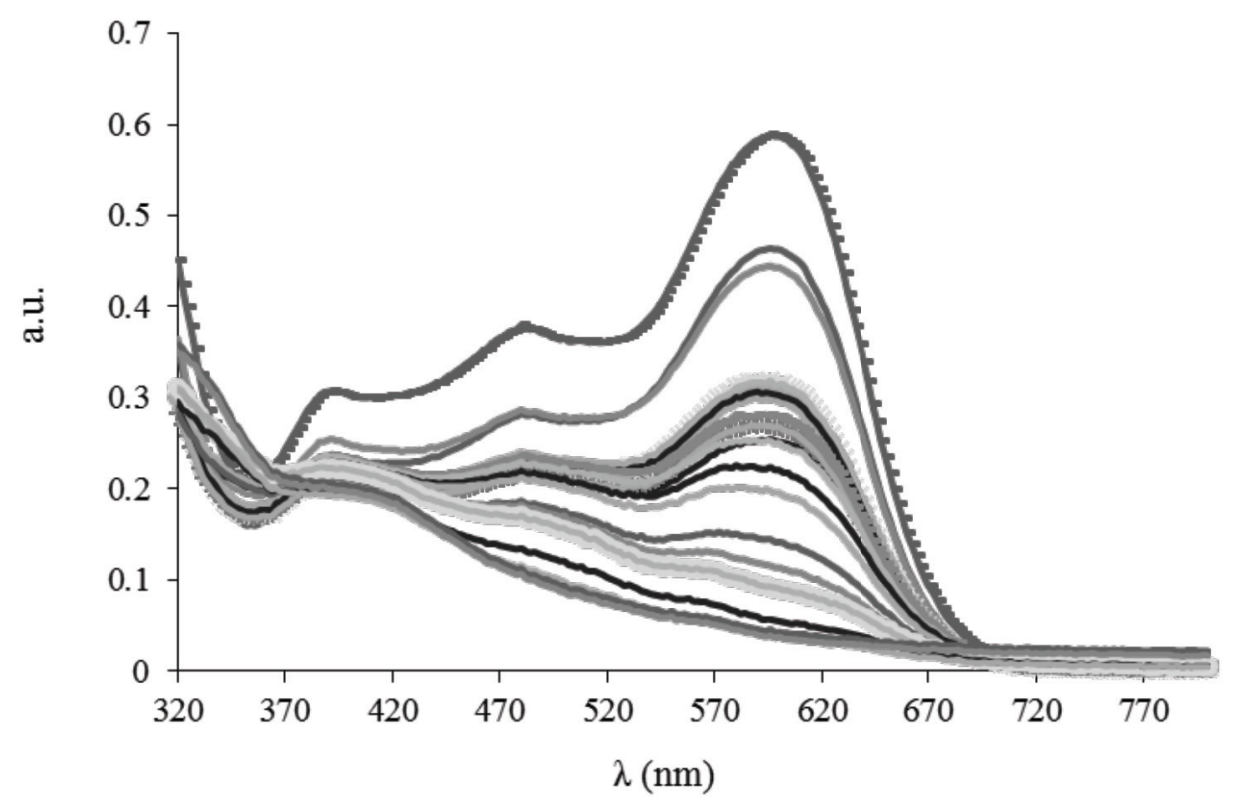


Fig. 8

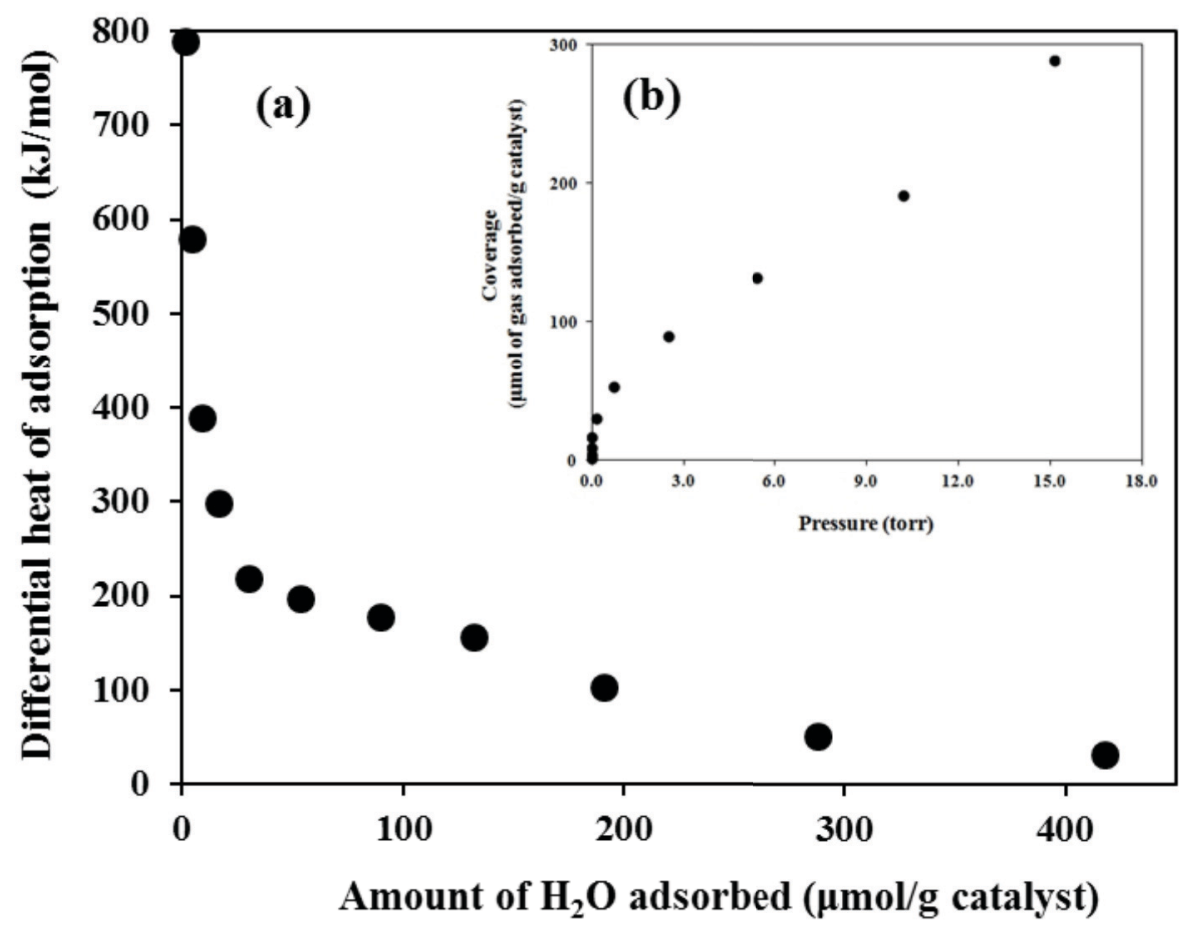

Fig. 9 